\title{
Combining remotely sensed spectral data and digital surface models for fine-scale modelling of mire ecosystems
}

\author{
M. Küchler ${ }^{1,3}$, K. Ecker ${ }^{1}$, E. Feldmeyer-Christe ${ }^{1}$, U. Graf $^{1}$, H. Küchler ${ }^{2}$ \\ and L. T. Waser ${ }^{1}$ \\ ${ }^{1}$ WSL, Swiss Federal Research Institute, Zürcherstrasse 111, 8903 Birmensdorf, Switzerland \\ E-mail:klaus.ecker@wsl.ch,elizabeth.feldmeyer@wsl.ch,ulrich.graf@wsl.ch,lars.waser@wsl.ch \\ ${ }_{2}^{2}$ Arvenweg 18,8840 Einsiedeln, Switzerland.E-mail:helen.kuechler@tiscali.ch \\ ${ }^{3}$ Corresponding author. Department of Landscape Inventories, Swiss Federal Research Institute WSL, \\ Zuercherstrasse 111,8903 Birmensdorf, Switzerland.E-mail: meinrad.kuechler@wsl.ch
}

Keywords: Composite modelling, Digital Elevation Model, GIS, Model calibration, Model evaluation, Orthoimages, Remote sensing, Swiss Mire Monitoring, Vegetation models.

\begin{abstract}
The detection and evaluation of changes in vegetation patterns is a prerequisite for monitoring programs. The Swiss mire monitoring program aims to assess the changes in mire vegetation in order to examine the efficiency of the management measures. A promising way to explore and detect vegetation structure and vegetation change is the application of predictive vegetation mapping that combines image classification and predictive habitat distribution models. These models deal with predictor variables derived from remotely sensed spectral data and from environmental variables such as a digital surface model (DSM). Low accuracy of environmental data to predict vegetation at the local scale is due to the difficulties to capture dominant fine-scale enironmental gradients. Using high resolution spectral and topographical data sets of $50 \mathrm{~cm}$ pixel size and below, the study presented here aims to improve the simulation of local-scale vegetation properties.
\end{abstract}

The spectral data for fine-scale modelling are based on CIR orthoimages with a ground resolution of $32 \mathrm{~cm}$. Various spectral variables and spectral-textural variables were derived for the modelling process. A new method to reduce the number of predictor variables, the composite modelling is presented in this paper. In comparison to existing methods, composite modelling has the advantage of being independent of the scale of the predictor variables, and at the same time being transferable among various data sets. Mean indicator values for moisture, nutrients and light derived from vegetation data are used as response variables. Results show that the topographical variables based on relief features are less powerful predictors than the spectral variables but that combining them enhances the overall predictive power. Stratification of the data according to the tree layer and the shadow areas increases the accuracy of the model.

Abbreviations: DSM - Digital Surface Model; DTM - Digital Terrain Model; DEM -Digital Elevation Model; CIR - Colour Infrared; NDVI - Normalized Difference Vegetation Index; EVI - Enhanced Vegetation Index; MSAVI2 - Modified Soil Adjusted Vegetation Index 2 .

\section{Introduction}

As new powerful statistical and GIS tools have been available, predictive habitat distribution models are increasingly used in ecology (Guisan and Zimmermann 2000). There is a growing need for sensitive tools to predict spatial and temporal patterns of plant species or communities (Kienast et al. 1996). The present study focuses on optimizing the prediction of vegetation properties for monitoring purposes on a fine scale.

Predictive vegetation mapping has developed over the past three decades. Research is driven by the demand from environmental planning and nature conservation and by the scientific interest in the quantitative analysis of the underlying relationship between vegetation and envi- ronment (Franklin 1995). Commonly applied mapping techniques can be divided into image classification procedures (Franklin 1995) and predictive habitat distribution models (Guisan and Zimmermann 2000). These modelling approaches rely on predictor variables that are derived from remotely sensed spectral data or from relief features. However, both data sources have inherent limitations for simulating vegetation, especially at the landscape level and below. Various non-floristic effects on the reflectance properties of vegetation units (Holopainen and Wang 1998, Dean et al. 2000, Gao et al. 2000, Broge and Leblanc 2001, Mikkola and Pellikka 2002, Brandtberg et al. 2003) and spectral similarities among floristic entities (Frank 1988, Treitz et al. 1992, Nilsen et al. 1999, Dirnböck et al. 2003) prevent the identification of floristic 
groupings in spatial detail. On the other hand, environmental variables only predict potential rather than existing vegetation and thus do not reflect stochastic disturbances and transient dynamics (Zimmermann and Kienast 1999).

Prediction results can be improved by combining the complementary strength of both data sources in a single modelling process in order to minimize the respective shortcomings (Hutchinson 1982, Warner et al. 1991, Warner et al. 1994, White et al. 1995, Treitz and Howarth 2000, Wiegand et al. 2000, Brossard et al. 2002). Recent models, that combine both data types to predict vegetation at the local scale, usually have to work with insufficiently accurate data which prevent them to capture the dominating fine-scale environmental gradients (Dullinger et al. 2001, Dirnböck et al. 2003).

The study presented in this paper employs high resolution spectral and topographical data sets of $50 \mathrm{~cm}$ pixel size and below to simulate fine-scale vegetation properties at the very local scale of Swiss mire sites. Among environmental measurements, biophysical parameters have little predictive power at this scale (Guisan and Zimmermann 2000). Therefore, topography is emphazised and analyzed as a surrogate for fine-scale surface energy budget, soil properties and water flow conditions (Moore et al. 1991, Dirnböck et al. 2002).

The study design was developed for a monitoring program to examine the efficiency of conservation measures required by the Federal Decree on Mire Conservation. The specific objective is to sample the entire variety of Swiss mire ecosystems and to provide fine-scale mapping results that are relevant to the given monitoring and conservation tasks. Therefore, high accuracy and wide applicability of the model predictions are both required.

The modelling itself relies on ordinary multiple linear regression and is calibrated by a field data sample. To find the optimal predictor variables, primary and compound attributes are derived from both, relief and spectral data sets, and tested in terms of predictive power and accuracy (Guisan and Zimmermann 2000). Since model performance decreases when the number of observations (i.e., calibration data) does not markedly exceed the number of predictor variables (Stahel 1995), the number of predictor variables has to be minimized. We employed a new method - termed composite modelling - to achieve variable reduction. This method combines the advantages of being independent from the scale of the predictor variables, and of being transferable among various data sets at the same time. Instead of plant species or communities, mean indicator values (i.e., indicator values averaged by sampling units) are employed as response variables (Ellenberg 1974, Landolt 1977, Ellenberg et al. 1992).

\section{Material and methods}

This study is part of the Swiss mire monitoring program initiated in 1996 at the Swiss Federal Research Institute WSL in partnership with the Swiss Agency for the Environment, Forest and Landscape. To provide valid data for the whole country, a stratified random sample was drawn from the mires listed in the federal mire inventories (Grünig et al. 1986, Broggi 1990). The sampling takes into account the geographic region, the altitudinal belt, the type (bog or fen) and the size of the mire. The resulting selection comprises 103 mire sites. Some additional mires were investigated as a reference to assess the causes of possible changes. The mire sites chosen for testing the model in this study belong to these reference mires.

\section{Study areas}

For our model development we choose the two study areas "Gross Moos" and "Les Sagnes de la Burtignière". "Gross Moos" is located in Schwändital on the northern slope of the Alps at an altitude of about $1250 \mathrm{~m}$. It is a percolated sloping bog of about 16 ha.

In the 1920's the farmers made an effort to transform the mire into pastures by draining it with a system of ditches. The result was the destruction of the hydrology of the mire, but no valuable pastures were gained. Up to about 1990, the entire site was grazed and therefore heavily degraded. Then the site became a protected area and the cattle was removed, first from the central parts and in 1996 from further areas.

In 2000, one of the big ditches in the centre was filled up with sawdust and sealed with palisades to raise the ground water level in the centre of the mire.

The second study area, the raised bog of La Burtignière is among the few bogs in the Jura mountains which are quite intact. It shows large patches of primary raised bog vegetation in the central part and fen communities on the fringe of the bog. Wet meadows and pastures surround the mire. Situated in the Vallée de Joux at a mean altitude of $1000 \mathrm{~m}$, the mire is in close relationship with the river Orbe, which lines it on its north-western part and meanders in a mostly unaltered state for $30 \mathrm{~km}$.

\section{Response variables}

In most of the sites investigated for the Swiss mire monitoring, field survey is restricted to a limited number 


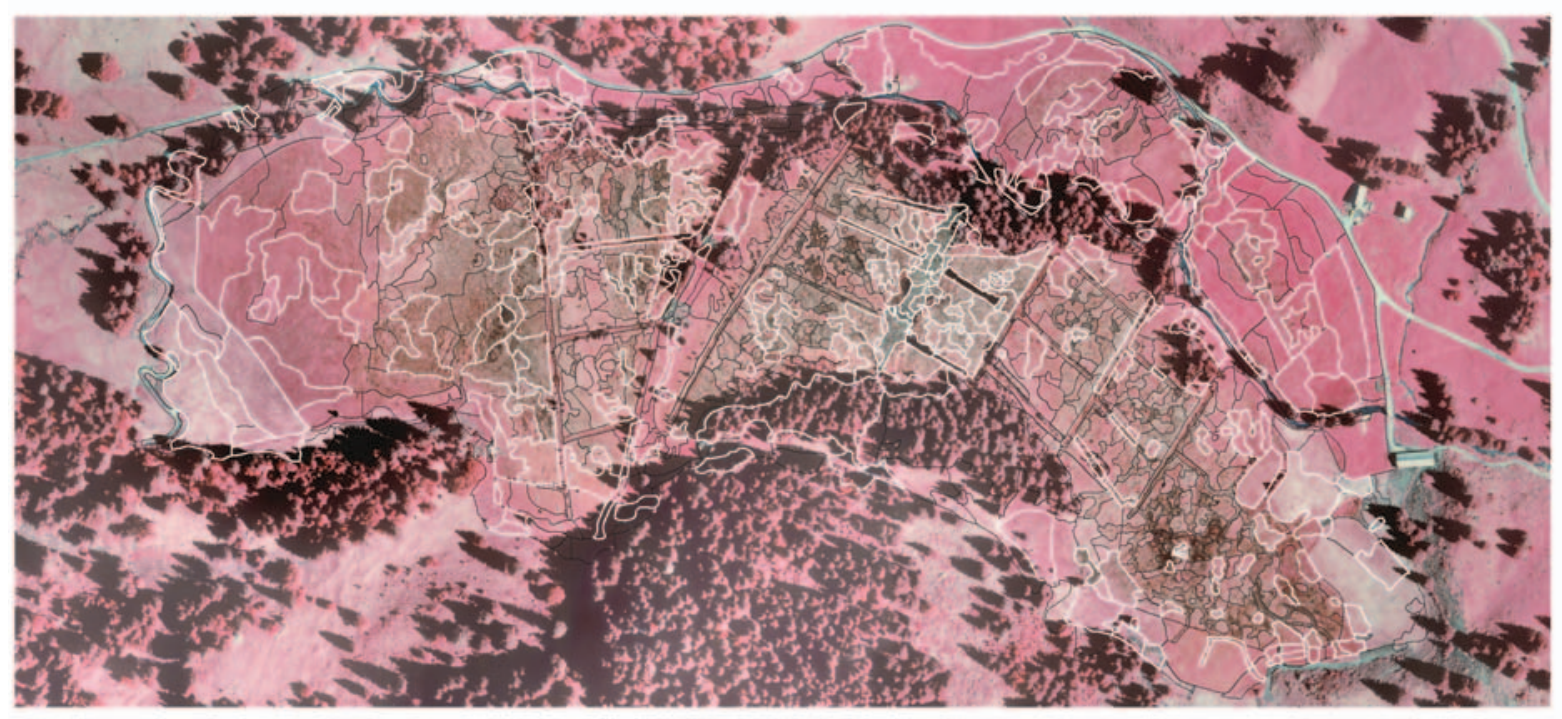

Figure 1. Orthoimage of Mire Schwändital taken in 2001 with an ortho-corrected a priori delineation of floristic groupings superimposed. The plots selected for field work are outlined in white.

of plots, selected by stratified random sampling (Fig. 1). Field work consists of a full record of vascular plants and bryophytes for each patch selected for investigation. In addition, some parameters such as tree cover, Sphagnum cover, open water, bare peat etc. are recorded.

In this study, three data sets are used: "Schwändital 1996" comprises about 1000 relevés covering the whole surface of the mire, recorded in 1995 and 1996. "Schwändital 2001" includes about 280 relevés of the same site which are a stratified random sample based on remotely sensed information (Fig. 1), recorded in 2001. The "Burtignière" data set consists of about 440 relevés taken in 1996, covering the whole surface of the mire.

Fully automatic and semi-automated procedures for image segmentation have been a main research focus in the area of image analysis for many years. Some algorithms (Woodcock and Harward 1992) were tested at the beginning of the monitoring program, but the results were not satisfactory for the complex floristic patterns and the delineation quality needed for field work and modelling purposes. Therefore in the present study image segmentation is realised by visual photographic interpretation of overlapping pairs of analogue CIR aerial photos with a scale of 1:5000 under a stereoscope. Vegetation patches are delineated which meet certain criteria of homogeneity in terms of colour, texture and structure.

Patches visited during field work can consist of both wooded and open parts. If the corresponding polygons (i.e., the plots delineated on the aerial photo) are subdivided into wooded segments and open segments (see the section "Stratification" for details), then the field data have to be split as well. The tree species and the herbaceous species growing under the trees have to be assigned to the wooded segments. However, the field records do not contain any information about the locations of plants within the patches. The woodland species have to be identified in an indirect way.

To do this, all relevés available from the Swiss mire monitoring program (i.e., about 20,000 relevés) are grouped into two classes: records with trees and bushes, and records without. The IndVal algorithm (Dufrêne and Legendre 1997, Legendre and Legendre 1998) applied to the presence - absence data results in three groups of species: (1) species typical for woodland, (2) species typical for open land, and (3) indifferent species. When modelling is applied to open land segments only, the woodland species as defined above are removed from the data set.

We selected indicator values as the main criterion to indirectly describe the vegetation and site properties since no ground geo-chemical and geo-physical measurements were available.

Indicator values characterize the physiological optima of organisms along multiple environmental gradients. The indicator values assigned empirically to vascular plants (Landolt 1977) for Switzerland and by Ellenberg (Ellenberg 1974, Ellenberg et al. 1992) for Central Europe are the most commonly used (Persson 1981, Diekmann and Dupre 1997, Hawkes et al. 1997, Hill and Carey 1997, Gegout et al. 2003). Landolt's values for moisture, light, temperature, continentality, nutrients, soil reaction, humus value and dispersity are scaled in ordinal levels from 1 to 5 . 
The indicator values used as response variables in this study are adapted for mire habitats on basis of 20,000 relevés from the Swiss mire monitoring program. The calibration is realized by calculating the mean indicator values of the relevés in which the considered species is present, and then computing the $10 \%$ trimmed mean of these relevé means. The procedure is repeated for any occurring species. Finally, the scale of the resulting metric values is adjusted by fitting the mean and the standard deviation of the new indicator value set to the range of Landolt's values. For further information about calibrating indicator values, see ter Braak (1995).

The indicator values selected for tests in this study are for moisture, nutrients and light. The response variables consist of the mean indicator values without weighting the species cover (i.e., the average per sampling unit, using presence - absence information).

\section{Spectral and topographical predictor variables}

Accurate CIR orthoimages with a ground resolution of $32 \mathrm{~cm}$ and a root mean square error (RMSE) of 5-25 $\mathrm{cm}$ constitute the spectral data base for fine-scale modelling. The aerial photographs offer three colour bands of numerical information (visible green: 500-600 nm, visible red: $600-700 \mathrm{~nm}$ and near infrared: $750-1000 \mathrm{~nm}$ ). Radiometric calibration methods are not applied.

The spectral predictor variables derived for the modelling process are compiled in Table 1 together with relief and surface descriptors. The variables are calculated from vegetation segments used as spatial modelling units. This list groups the variables in thematically coherent classes. It specifies the number of variables comprised in each variable group and indicates the way of derivation and the respective environmental relevance.

Accordingly, we compute various colour band values and colour band ratios for each delineated polygon or its possible subsegment in case of stratification (see subsection "Stratification"). Such band-ratio techniques are commonly applied to reduce the effect of varying illumination and topography on reflectance properties (Bajwa and Tian 2002). To consider vegetation-specific band ratios, the Normalised Difference Vegetation Index (Richardson and Wiegand 1977, Wiegand et al. 1991), Enhanced Vegetation Index (Huete et al. 2002) and Modified Soil Adjusted Vegetation Factor 2 (Qi et al. 1994) were calculated.

To capture fine-scale textural characteristics, the multiple colour information is simplified by an unsupervised classification, using the ISODATA clustering algorithm based on the migrating means technique and the mini- mum Euclidian distance (Richards 1993). We thus group the numerical three-band information into 24 discrete classes within one layer. Then, contiguity indices are calculated for each colour class in a moving window of $3 \times$ 3 pixels to determine relative colour class proportions (percentage of each colour class), colour class agglomerations and homogeneity of the colour class distributions (see Table 1, for details). Given a pixel size of $32 \mathrm{~cm}$, the evaluated area of one square meter is likely to reflect vegetation composition in spectral detail.

A digital terrain model with a ground resolution of 25 m (DHM25@2003 Bundesamt für Landestopographie DV 455.2) is used to assess vegetation response to broadscale topographical gradients. Prior to computations, the terrain model is smoothed and resampled to a resolution of $1 \mathrm{~m}$.

Northing, easting and terrain slope indices are calculated for the centroid label (ESRI 1995) to describe the polygon's exposure (for a full list of the topographical predictors see Table 1). Additionally, a compound topographic index (Curvature25) is computed to describe the convexness of a location and to emphasize topographic features such as ridge, slope, slope bottom and sink. The applied algorithm calculates the concaveness or convexness of a topographic position within a varying moving window radius of 10 to $30 \mathrm{~m}$ and hierarchically integrates the most extreme measures into a single grid (for details about the algorithm, see Zimmermann 2000).

For assessing fine-scale vegetation structure and topography stereo matching techniques are applied to generate DSMs with a resolution of $50 \mathrm{~cm}$ (Ginzler and De Laporte 2001). The resulting relief represents ground terrain or objects on the ground. It even reveals small elements such as single trees and bushes (Fig. 2).

Slope and curvature indices are derived from the DSM $50 \mathrm{~cm}$ as described above for the DTM. Curvature 05 is calculated within a varying moving window radius of 2 to $5 \mathrm{~m}$ and for open land only by excluding surface objects hiding the ground (for the procedure of excluding surface objects see subsection "Stratification"). Again, image processing techniques are applied to compute textural characteristics such as surface composition and roughness. These features are considered to be important e.g., for the recognition of tree canopies. As with the classification process described for spectral data, continuous slope values are grouped into eight classes and processed by moving window techniques $(3 \times 3$ pixels $)$ to calculate relative class proportions and contiguity measures. 
Table 1. Spectral and topographical predictor variables used for simulating a priori delineated polygons or possible sub-segments in case of stratification. The variables are arranged in thematically coherent sections. The table describes the variable groups employed for modelling (see section ,Statistical model"). Columns 2, 3 and 4, respectively, give the number of variables comprised in each variable group, their data source and the respective derivation.

\begin{tabular}{|c|c|c|c|c|}
\hline $\begin{array}{l}\text { Predictor variable } \\
\text { group }\end{array}$ & $\mathrm{Nr}$ & Data source & Derivation (based on vegetation segments) & Environmental relevance \\
\hline \multicolumn{5}{|l|}{ Spectral variables } \\
\hline Colour bands & 9 & ClR image & $\begin{array}{l}\text { Mean, median and variance of the CIR colour } \\
\text { bands: } \\
\text { nir: near infrared }(750-1000 \mathrm{~nm}) \\
\text { red: visible red }(600-700 \mathrm{~nm}) \\
\text { green: visible green }(500-600 \mathrm{~nm})\end{array}$ & $\begin{array}{l}\text { Spectral reflectance, absorption } \\
\text { and transmission of the } \\
\text { vegetation cover }\end{array}$ \\
\hline Colour band ratios & 6 & CIR image & $\begin{array}{l}\text { Ratio of each colour band mean to the sum of all } \\
\text { band values } \\
\text { Ratio of each colour band median to the sum of all } \\
3 \text { band values }\end{array}$ & $\begin{array}{l}\text { Calibrated spectral reflectance, } \\
\text { absorption and transmission of } \\
\text { the vegetation cover }\end{array}$ \\
\hline NDVI & 3 & CIR image & $\begin{array}{l}\text { Mean, median and variance of the Normalised } \\
\text { Difference Vegetation Index: (nir - red) / (nir + red) }\end{array}$ & $\begin{array}{l}\text { LAl, chlorophyll content, above- } \\
\text { ground phytomass, net primary } \\
\text { production } x x x\end{array}$ \\
\hline $\mathrm{EVI}$ & 3 & CIR image & $\begin{array}{l}\text { Mean, median and variance of the Enhanced } \\
\text { Vegetation Index: } 2.5^{*}(\text { nir }- \text { red }) /(\text { nir }+ \text { red }+ \\
\left.5^{*} \text { red }+7.5^{*} \text { green }+1\right)\end{array}$ & $\begin{array}{l}\text { Modification of the NDVI } \\
\text { including an atmospheric } \\
\text { correction factor }\end{array}$ \\
\hline MSAVI2 & 3 & CIR image & $\begin{array}{l}\text { Mean, median and variance of the Modified Soil } \\
\text { Adjusted Vegetation Index } 2: 0.5^{*}\left(2^{*}(\text { nir }+1)-\right. \\
\left.\left(2^{*} \text { nir }+1\right)^{\wedge} 2-8^{*}(\text { nir }- \text { red })^{\wedge} 0.5\right)\end{array}$ & $\begin{array}{l}\text { Simple transformation of the } \\
\text { NDVI }\end{array}$ \\
\hline
\end{tabular}

Spectral-textural

variables

\begin{tabular}{|c|c|c|c|c|}
\hline $\begin{array}{l}\text { Colour class } \\
\text { proportions }\end{array}$ & 24 & $\begin{array}{l}\text { image } \\
\text { classification }\end{array}$ & Relative proportions of each colour class (24) & $\begin{array}{l}\text { Proportions of spectrally similar } \\
\text { vegetation units }\end{array}$ \\
\hline $\begin{array}{l}\text { Colour class } \\
\text { agglomeration }\end{array}$ & 24 & $\begin{array}{l}\text { image } \\
\text { classification }\end{array}$ & $\begin{array}{l}\text { Mean numbers of each colour class ( } 24) \text { in a } 3 \times 3 \\
\text { pixel window }\end{array}$ & $\begin{array}{l}\text { Spatial distribution of spectrally } \\
\text { similar vegetation units }\end{array}$ \\
\hline $\begin{array}{l}\text { Colour class } \\
\text { homogeneity }\end{array}$ & 24 & $\begin{array}{l}\text { image } \\
\text { classification }\end{array}$ & $\begin{array}{l}\text { Variances of the number of each colour class (24) } \\
\text { in a } 3 \times 3 \text { pixel window }\end{array}$ & $\begin{array}{l}\text { Spatial distribution of spectrally } \\
\text { similar vegetation units }\end{array}$ \\
\hline
\end{tabular}

\section{Topographical}

variables

\begin{tabular}{lllll}
\hline Exposure & 3 & DTM $25 \mathrm{~m}$ & $\begin{array}{l}\text { Mean terrain slope, north- and east-exposed } \\
\text { fractions of aspect at the polygon centroid }\end{array}$ & $\begin{array}{l}\text { Broad-scale surface energy } \\
\text { budget, evapotranspiration and } \\
\text { water flow conditions } \\
\text { Broad-scale soil properties and } \\
\text { water flow conditions, } \\
\text { topographic features like ridge, } \\
\text { slope, slope bottom and sink }\end{array}$ \\
Curvature05 & 3 & DTM $25 \mathrm{~m}$ & $\begin{array}{l}\text { Mean, median and variance of the concave- or } \\
\text { convexness within a varying moving window } \\
\text { radius of } 10 \text { to } 30 \mathrm{~m} \text { (the DTM is smoothed and } \\
\text { resampled to a cell size of } 0.5 \mathrm{~m} \text { ): } \\
\text { Mean, median and variance of the concave- or } \\
\text { convexness within a varying moving window } \\
\text { radius of } 2 \text { to } 5 \mathrm{~m} \text { in open land. }\end{array}$ & $\begin{array}{l}\text { Fine-scale soil properties and } \\
\text { soil water conditions, } \\
\text { topographic features like } \\
\text { drainage ditch, hummock, hollow } \\
\text { Fine-scale water flow conditions, } \\
\text { surface roughness }\end{array}$ \\
\hline
\end{tabular}

Topographical-textural

\begin{tabular}{|c|c|c|c|c|}
\hline $\begin{array}{l}\text { Slope class } \\
\text { proportions }\end{array}$ & 8 & DSM $0.5 \mathrm{~m}$ & Relative proportions of 8 slope classes & Surface composition \\
\hline $\begin{array}{l}\text { Slope class } \\
\text { agglomeration }\end{array}$ & 8 & DSM $0.5 \mathrm{~m}$ & $\begin{array}{l}\text { Mean numbers of } 8 \text { slope classes in a } 3 \times 3 \text { pixel } \\
\text { window }\end{array}$ & Surface roughness \\
\hline $\begin{array}{l}\text { Slope class } \\
\text { homogeneity }\end{array}$ & 8 & DSM $0.5 \mathrm{~m}$ & $\begin{array}{l}\text { Variances of the numbers of } 8 \text { slope classes in a } \\
3 \times 3 \text { pixel window }\end{array}$ & Surface roughness \\
\hline
\end{tabular}



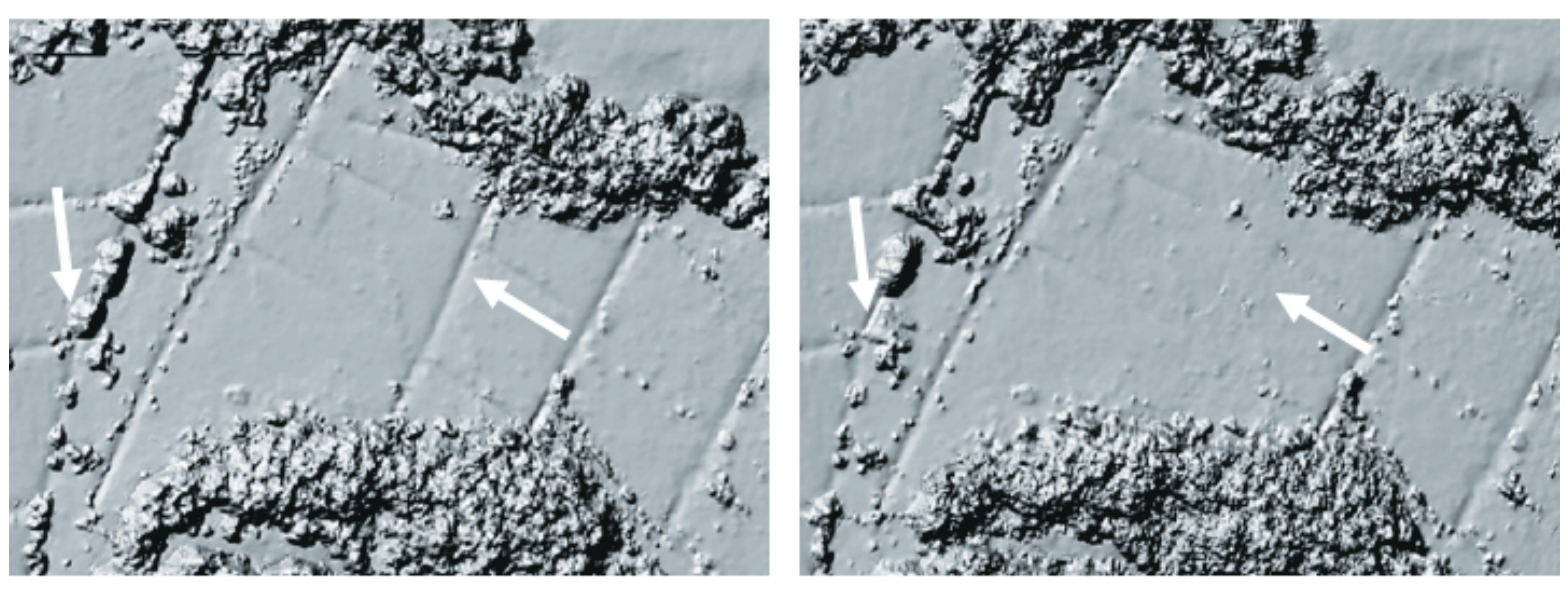

Figure 2. Perspective view of shaded DSMs $(50 \mathrm{~cm}$ resolution) representing two temporal stages of the same mire (Schwändital). Fine-scale terrain and surface changes such as the refilling of a drainage ditch or a tree being overturned (see arrows) are clearly documented. (Generating tool: ATE, a component of the photogrammetry workstation SocetSet from LHSystems.)

\section{Stratification}

Stratifications were applied in order to pre-select the model data sets, by i) shadow and ii) tree layer masking. Field data and remotely sensed data are expected to show little correlation in areas which are covered by objects on the ground or are affected by shadow. Therefore, we suppose that distinguishing shadow-free open land and hidden ground areas may enhance the predictive capability of our model.

Today, airborne laser scanning and radar techniques provide powerful tools to separate ground surface from objects on the ground (Lim et al. 2003). Since multiple surface data were not available in this study, an alternative multi-stage procedure is applied to mask all objects that bulge on the terrain. The method relies upon surface models (DSM $50 \mathrm{~cm}$, DTM $25 \mathrm{~m}$ ) in conjunction with spectral data.

A normalized DSM is used to calculate a preliminary tree layer (Fig. 3). The algorithm developed incorporates a slope threshold, minimum segment sizes for tree canopy and gaps, noise filters as well as expand and shrink functions to produce compact polygons.

The resulting layer contains two types of systematic errors. First, it reproduces systematic errors of the stereo matching process which tends to create by mistake pyramids in structure-poor areas such as lake surfaces or harvested fields. Second, trees and bushes might be mixed up with steep fine-scale terrain elements such as road or doline slopes and with similar shaped surface objects such as houses, cars or cows.
In a post-processing step, most of these errors are identified and cleared semi-automatically using objectbased image processing techniques. The procedure comprises hierachical image segmentation based on a bottomup region merging technique (Baatz and Schäpe 2000) and image classification using membership functions with robust band-ratios. Due to distinct spectral characteristics of the focused objects, little manual adjustment is necessary to considerably improve the accuracy of the tree layer.

\section{Statistical model}

The response values used in this study are mean indicator values for moisture, nutrients and light, derived from the vegetation data recorded in the field. The scale of these indicator values is continuous. Therefore, a linear regression model is expected to be suitable for predicting the site properties described by mean indicator values. The modelling chosen for this study is based on ordinary least square regression. In order to satisfy linearity conditions, some of the predictor variables listed in Table 1 are transformed. Variances are replaced by their square root before entering the model, proportions are transformed by computing the arc sine of the square root (Zar 1986, Schlittgen 2000).

In multiple linear regression models, the number of predictor variables is restricted by the number of observations. If there are fewer observations than variables, the model is statistically undetermined. If the number of observations is not considerably higher than the number of variables, the modelling results will not be reliable (see e.g., Stahel 1995). Commonly used methods to reduce the 
number of predictor variables are principal component analysis (Mardia et al. 1979, Johnson and Wichern 1982, Dillon and Goldstein 1984) and stepwise model selection (Draper and Smith 1981, Miller 1984, Miller 1990).

Principal component analysis yields results which depend on the scales of the variables. If there is no theoretically founded way to compare the scales of the variables, principal components will be difficult to interpret with respect to a response variable which in our case is an indicator value.

Stepwise model selection optimizes the model fit and not necessarily the predictive power of a model. It can be useful in validation of models when development is ongoing, but it cannot replace background knowledge about the variables entering the model.

To avoid these shortcomings, a new method is tested which we will call composite modelling. It consists of two steps: (1) fitting individual models to thematically coherent groups of predictor variables (such as those listed in Table 1, every row corresponding to a variable group), (2) calculating a second level model based on the fitted values resulting from the first models (which represent a reduced data space in analogy to principal component axes).

In this study, models using two or more predictor variable groups are Composite Models, whereas models comprising only one variable group are simple multiple regressions.

\section{Model performance}

To validate the predictive power and the accuracy of the models and variables, or the effect of stratification, the data sets are subdivided into calibration samples and control samples.

The correlations between the predicted values and the corresponding observed control data values are taken as a measure of the predictive capacity of models.

To quantify the predictive power, score points are assigned to correlations. Correlations of 0.8 and higher get 4 points, correlations between 0.7 and 0.8 get 3 points, correlations between 0.6 and 0.7 get 2 points and correlations between 0.5 and 0.6 get 1 point. Correlations below 0.5 get no points. The performance of the predictor variables is tested by a predefined set of 9 trials (see last paragraph of this section). The performance scores of the 9 trials are added up, so that the maximum total score is 36 points $(9 \times 4$ points $)$.

The accuracy of a model can be estimated by analyzing the absolute differences between each predicted value and its corresponding control data value (i.e., the absolute errors). Among various possible parameters (such as the mean, the median or arbitrary quantiles) of the absolute errors, the $95 \%$ quantile is chosen as accuracy measure in the present study.

If two or more predictor variables are highly correlated, adding to the model more than one of them will in-

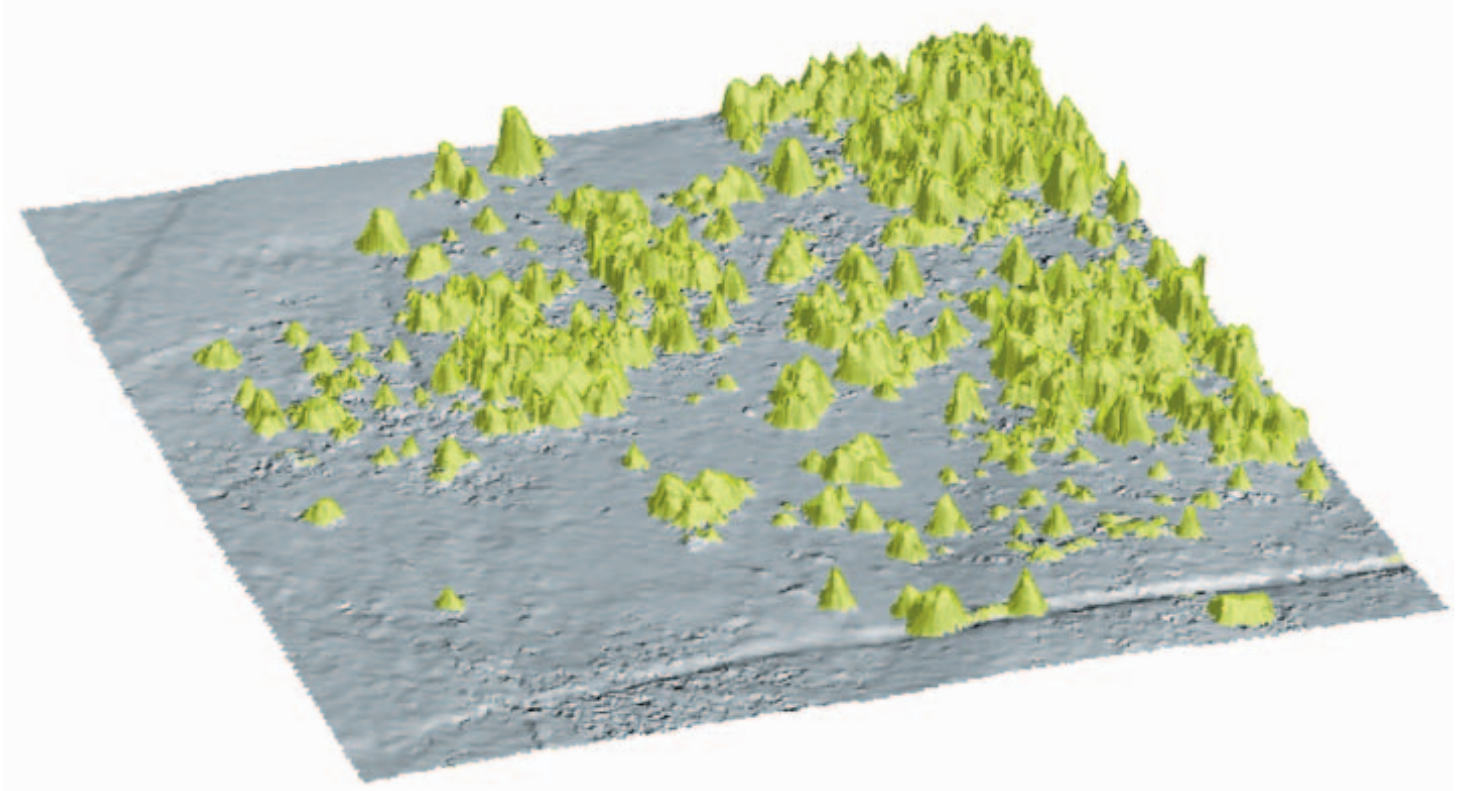

Figure 3. Preliminary tree layer (green), superimposed to a normalized, hillshaded DSM (50 $\mathrm{cm}$ resolution), also displaying an object of no interest (small house in the right front). 
crease only little the amount of data variance explained. Once one of the correlated variables is included in the model, the other can be regarded as redundant.

A widely used method to eliminate such redundant variables is stepwise model selection, existing in several modifications (forward, backward, etc., see Draper and Smith 1981, Miller 1984, Miller 1990). In this study, we use backward stepwise model selection, based on the AIC criterion (Osborne 1976) .

If a given predictor variable is repeatedly eliminated from various models using data from various mire sites, we can assume that it adds little to the prediction of mire site properties. Thus, performing a predefined set of model selections and counting how many times given variables drop out can help to find redundancies.

If vegetation properties are to be predicted by using remotely sensed data, the modelling might be expected to work best when the ground surface is free from hidden areas such as trees and shadow. In order to check this assumption, the following data sets are derived from the mire site data (Schwändital 1996, Schwändital 2001, Burtignière):

- Data set 1 (no stratification) includes the spectral and topographical data of all segments delineated on the orthoimage, including areas covered by trees and shadow.

- Data set 2 (partial masking) excludes the patches which are covered totally by trees or shadow, i.e., the patches without any sight of the ground are masked.

- Data set 3 (full masking) excludes every segment covered by trees or shadow, i.e., segments within patches are masked if they are covered by trees or shadow. Only the parts of patches with full sight onto the ground vegetation are evaluated.

To quantify the effect of masking hidden areas on model performance, composite models for the three masking levels are tested. The models include all predictor variables listed in Table 1.

The model performances are tested using the following design:

- The tests (except the test for stratification) are carried out for shadow-free open land. Wooded and shaded areas are ignored as well as segments smaller than $10 \mathrm{~m}^{2}$.
- Each of the three data sets is subdivided into a calibration set of 100 randomly sampled relevés and a control comprising the remaining data.

- For each of the three data sets, moisture, nutrient and light indicator values are modelled, which results in nine combinations of sites and indicator values.

- The calculations aimed at correlations and accuracy are repeated 20 times for each of the nine combinations, drawing a new calibration sample (100 relevés) every time. The final result consists of the $10 \%$ trimmed means of correlations and quantiles resulting from the 20 repetitions, i.e., nine correlation values and nine quantile values according to the nine combinations of sites and indicator values. The calculations involving model selection are repeated ten times each, resulting in $3 \times 3 \times 10=90$ model formulae generated by stepwise variable dropping.

\section{Results}

\section{Predictive power of single variable groups}

Table 2 shows the performance scores of the single variable group models. The scores presented have to be interpreted as in the following example: e.g., the EVI variable group achieved correlations up to 0.7 . In one of the nine trials, the correlation was between 0.6 and 0.7 , which gets 2 score points. Four trials resulted in a correlation falling between 0.5 and 0.6 , which is 1 point each, so that the total score of all nine trials is 6 points. The four trials with correlation values below 0.5 get no points.

The scores of the textural variables derived from colour bands are highest, even higher than the scores of the colour bands themselves, just as the textural variables derived from slope values yield higher scores than the slope values themselves. Compound textural values seem to be more powerful predictors than primary attributes.

Within the data sets used for this test, variables based on relief characteristics (DTM $25 \mathrm{~m}$ and DSM $50 \mathrm{~cm}$ ) are less powerful predictors than the spectral variables (see Table 2). Even though the ranking of certain variable groups may be low, combining them can yield remarkable scores (e.g., as can be seen with the combination of Curvature05 and MSAVI2).

\section{Redundant predictor variable groups}

The results of backward stepwise model selections among predictor variable groups are shown in Table 3. The values displayed in this table have to be interpreted as in the following example: the NDVI variable group 
Table 2. Performance scores of each predictor variable group within open land. Every score is based on 9 correlation values. See Methods section, for details.

\begin{tabular}{|c|c|c|c|c|c|c|c|c|c|c|c|c|c|c|c|c|}
\hline 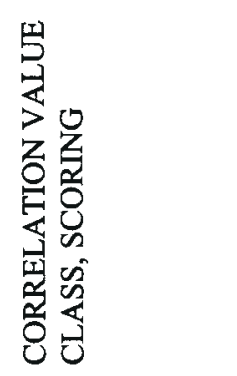 & 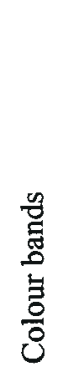 & 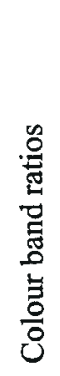 & 釜 & 点 & $\underset{\sum}{\stackrel{Q}{\&}}$ & 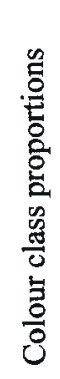 & 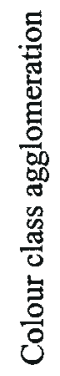 & 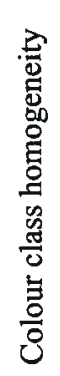 & 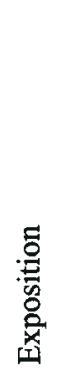 & 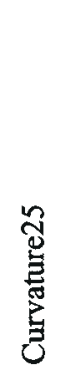 & $\frac{\check{O}}{\mathscr{\sigma}}$ & 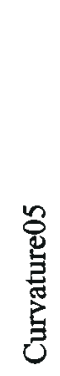 & 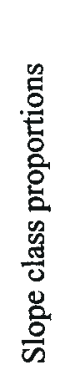 & 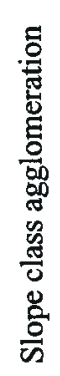 & 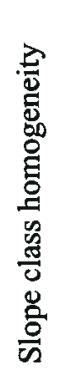 & 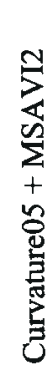 \\
\hline \multicolumn{17}{|c|}{ COUNTS of correlation values per class $($ column sums $=9$ ) } \\
\hline$>0.8$ (4 pts each) & 2 & 1 & 0 & 0 & 0 & 1 & 1 & 1 & 0 & 0 & 0 & 0 & 0 & 0 & 0 & 0 \\
\hline $0.7-0.8(3 \mathrm{pts})$ & 3 & 3 & 0 & 0 & 0 & 6 & 6 & 5 & 0 & 0 & 0 & 0 & 0 & 0 & 0 & 0 \\
\hline $0.6-0.7(2 \mathrm{pts})$ & 2 & 1 & 2 & 1 & 0 & 1 & 1 & 2 & 1 & 0 & 0 & 0 & 0 & 0 & 0 & 4 \\
\hline $0.5-0.6(1 \mathrm{pt})$ & 2 & 4 & 1 & 4 & 4 & 1 & 1 & 1 & 2 & 2 & 1 & 0 & 2 & 2 & 1 & 4 \\
\hline$<0.5(0 \mathrm{pts})$ & 0 & 0 & 6 & 4 & 5 & 0 & 0 & 0 & 6 & 7 & 8 & 9 & 7 & 7 & 8 & 1 \\
\hline \multicolumn{17}{|c|}{ SCORES (maximum possible $=36$ ) } \\
\hline & 23 & 19 & 5 & 6 & 4 & 25 & 25 & 24 & 4 & 2 & 1 & 0 & 2 & 2 & 1 & 12 \\
\hline
\end{tabular}

Table 3. Counts of each variable group remaining in final models after stepwise model selection (starting with all groups). Data: shadow-free open land. Number of trials: 10 per study area and indicator value $=$ total of 90 .

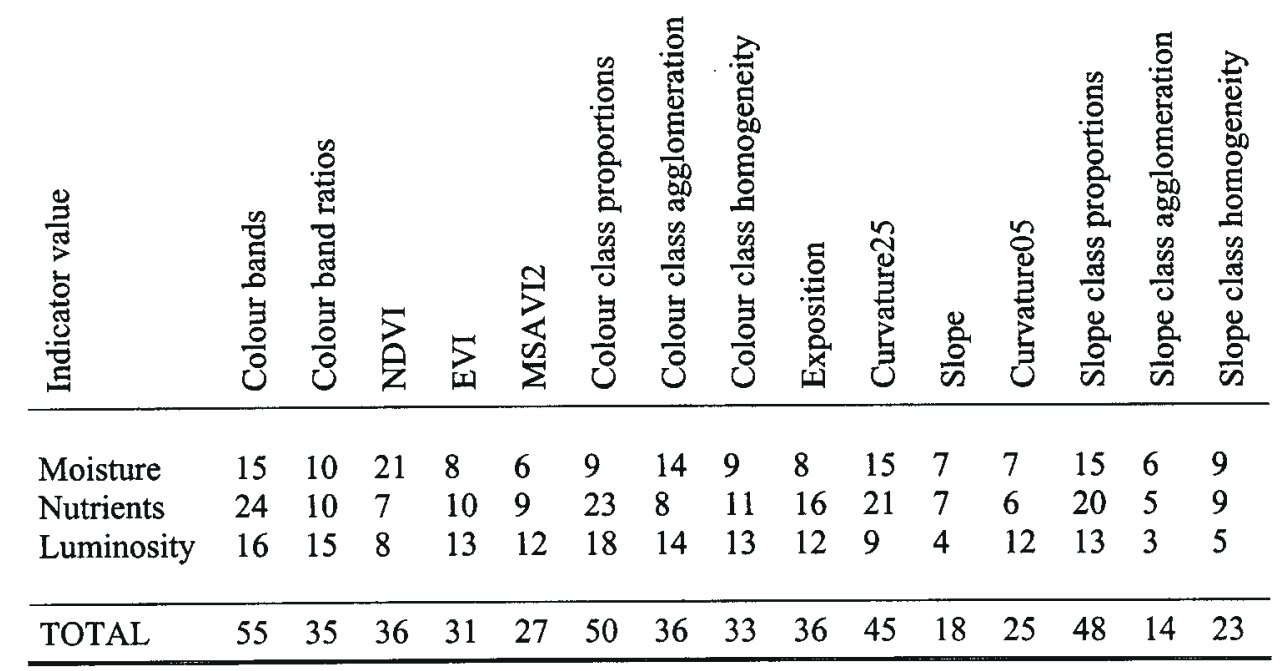

was retained in 21 of 30 models predicting mean moisture indicator values, indicating a high relevance of the NDVI variable group for modelling the moisture site factor. In the models for nutrients and light, the same variable group remained in seven models predicting mean nutrient values and in eight models predicting mean light values. In total, the NDVI variable group entered into 36 of the 90 final models.

Each of the 15 variable groups remained in more than 10 of the 90 final models. This means that every variable group contributes significant information to the model. However, this result is not sufficient to detect all redundancies. If there are two redundant variable groups, one of them will be eliminated from the model. It is accidental which of the two will remain in the model. Therefore, the matrix of the variable groups remaining in the final models has been analyzed visually.

The variable groups Curvature05 and Slope05 occurred together only once, thus indicating a high redundancy of this pair of variable groups. The same is true for 
Table 4. Performance of models based on (1) unstratified data, (2) data excluding patches covered completely by trees or shadow, (3) data from shadow-free open land segments only (see "Methods" section). Units according to Landolt (1977).

\begin{tabular}{|c|c|c|c|c|c|c|c|}
\hline \multirow[t]{2}{*}{ Site } & \multirow[t]{2}{*}{$\begin{array}{l}\text { Indicator } \\
\text { value }\end{array}$} & \multicolumn{2}{|l|}{$\begin{array}{l}\text { data sets } \\
1 \text { (no } \\
\text { masking) }\end{array}$} & \multicolumn{2}{|l|}{$\begin{array}{l}\text { data sets } \\
2 \text { (trees } \\
\text { and } \\
\text { shadow } \\
\text { partially } \\
\text { masked) }\end{array}$} & \multicolumn{2}{|l|}{$\begin{array}{l}\text { data sets } \\
3 \text { (trees } \\
\text { and } \\
\text { shadow } \\
\text { fully } \\
\text { masked) }\end{array}$} \\
\hline & & $\begin{array}{l}\text { Corre- } \\
\text { lation } \\
\text { (control) }\end{array}$ & $\begin{array}{l}95 \% \\
\text { quantile } \\
\text { of errors } \\
\text { (control) }\end{array}$ & $\begin{array}{l}\text { Corre- } \\
\text { laton } \\
\text { (control) }\end{array}$ & $\begin{array}{l}95 \% \\
\text { quantile } \\
\text { of errors } \\
\text { (control) }\end{array}$ & $\begin{array}{l}\text { Corre- } \\
\text { lation } \\
\text { (control) }\end{array}$ & $\begin{array}{l}95 \% \\
\text { quantile } \\
\text { of errors } \\
\text { (control) }\end{array}$ \\
\hline Burtignière & Moisture & 0.585 & 0.395 & 0.562 & 0.389 & 0.626 & 0.458 \\
\hline Schwändital 96 & Moisture & 0.735 & 0.371 & 0.705 & 0.373 & 0.688 & 0.401 \\
\hline Schwändital 01 & Moisture & 0.773 & 0.342 & 0.757 & 0.341 & 0.799 & 0.365 \\
\hline Burtignère & Nutrients & 0.862 & 0.757 & 0.881 & 0.695 & 0.874 & 0.770 \\
\hline Schwändital 96 & Nutrients & 0.804 & 0.683 & 0.798 & 0.647 & 0.803 & 0.635 \\
\hline Schwändital 01 & Nutrients & 0.854 & 0.589 & 0.857 & 0.571 & 0.882 & 0.568 \\
\hline Burtignère & Luminosity & 0.642 & 0.274 & 0.645 & 0.258 & 0.748 & 0.203 \\
\hline Schwändital 96 & Luminosity & 0.721 & 0.258 & 0.680 & 0.235 & 0.742 & 0.152 \\
\hline Schwändital 01 & Luminosity & 0.688 & 0.252 & 0.646 & 0.233 & 0.783 & 0.130 \\
\hline
\end{tabular}

the variable group pair Curvature05 and Slope class agglomeration. But considering the flat topography of the mire sites investigated for this study it might be premature to drop these variables definitely.

\section{Performance of composite models}

The predictive power and accuracy of the composite models using all variable groups are presented in Table 4. High correlation refers to high predictive power and a small error quantile reflects high accuracy. The overall performance of the composite models presented in Table 4 is higher than the performance of models comprising only a part of the available predictor variables (Table 2). This confirms the relevance of all variable groups for explaining data variance.

The predictive power and accuracy of the models differ for the response variables. The predictive power is better for the nutrient values (the correlations mostly lying between 0.8 and 0.9 ) than for moisture and light values which lie between 0.65 and 0.8 . The best accuracy of the models is for the light values (most of the error quantiles lying between 0.15 and 0.25 ), followed by the moisture values (between 0.35 and 0.45 ) and nutrient values (between 0.63 and 0.77 ).

These values can be taken only for comparisons within models aimed at the same response variable. An absolute interpretation would yield contradictory statements. For example, the models predicting nutrient values have both high correlations and high error quantiles with respect to the models predicting moisture or light values, which would denote a higher predictive power, but a lower accuracy. Actually correlations and error quantiles depend on the variability of the modelled site factor within the particular mire.

There are different model performances for different survey dates. The better performance of the models for moisture and nutrient values on Schwändital 2001 in comparison with Schwändital 1996 can be explained through the better quality of the spectral and topographical data available for 2001 .

There are also different model performances for different mire sites. The model for the moisture indicator value in the Burtignière mire is weaker than the corresponding model in Schwändital 2001, whereas the nutrient and light models show similar performances. This can be explained by the different variability of the corresponding site factors in the two mires.

\section{Effect of stratification on model performance}

Masking areas which are covered by trees or shadow enhances the performance of the models (see Table 4). According to correlations between predicted and observed values in the control data sets, the models with fully masked trees and shadow have the highest predictive power. In terms of accuracy measured by error quantiles, the models with partial masking are nearly equivalent to 
$\mathbf{a}$
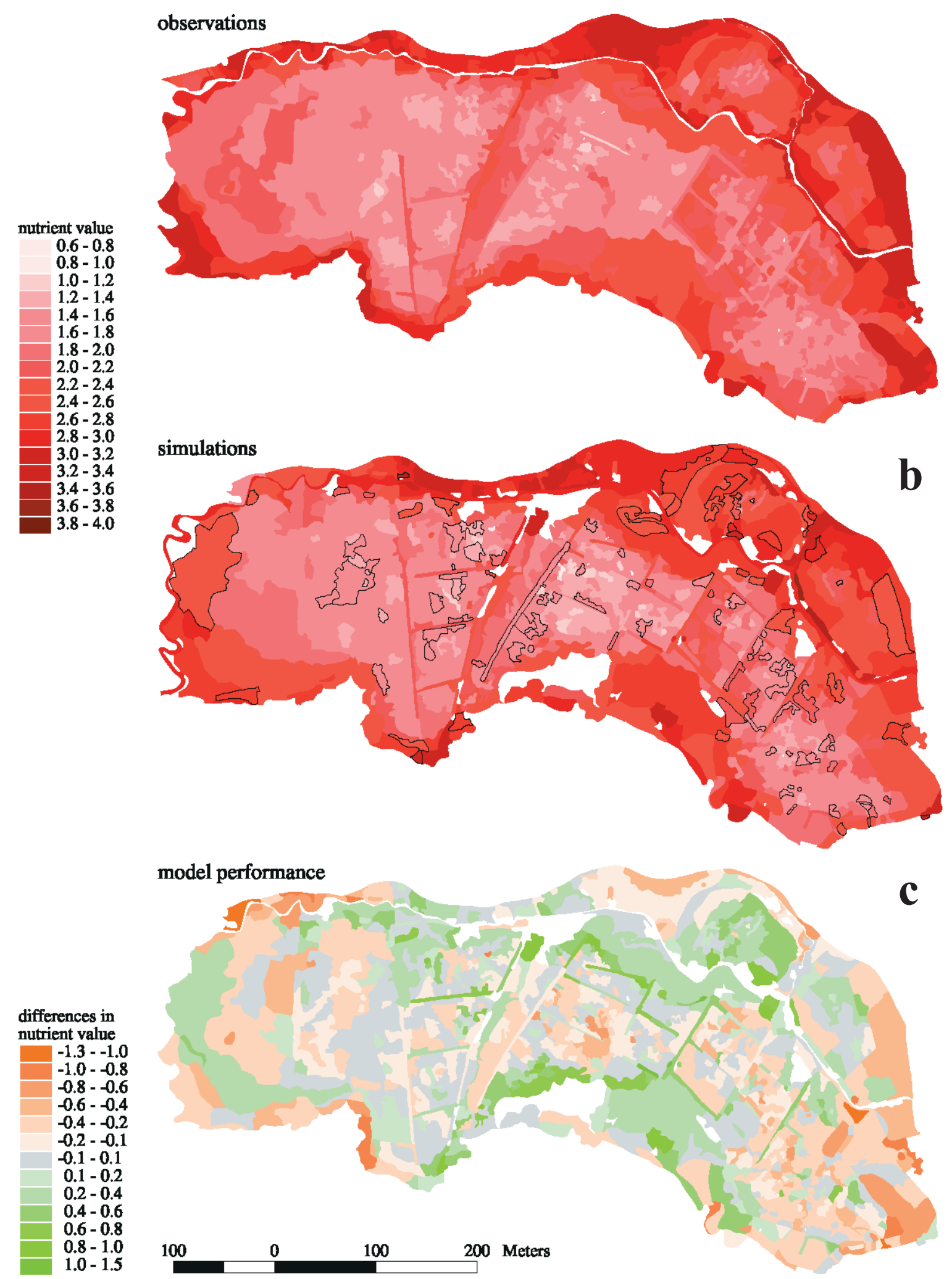

Figure 4. Map of mean nutrient values in Schwändital in 1996. a. observed values; b. modelled values, the calibration set is outlined; c. differences between modelled values and observed real values. 
the models with full masking of trees and shadow. The models without masking are the weakest.

Masking hidden areas markedly enhanced the performance of models aimed at light, whereas the effect on models predicting nutrient or moisture values is smaller.

In order to illustrate the performance of a model, Fig. 4 displays the nutrient indicator values derived from observed field data directly, the nutrient values predicted on the basis of 100 field relevés and finally the differences between the two values. The data are from Schwändital 96, without masking areas covered by trees or shadow. The correlation of the predicted and observed data values is 0.8 , the $95 \%$ quantile of errors is 0.68 .

The map based on predictions (Fig. 4b) well reflects the values derived from observations (Fig. 4a). On both figures $4 \mathrm{a}$ and $4 \mathrm{~b}$, the main structures of the mire site are visible. The nutrient-poor bog centre is surrounded by nutrient-rich pastures and tall-herb communities. Big ditches and a natural runoff cross the mire.

A closer inspection of details reveals differences between the predicted and the observed nutrient values. For example, all ditches are predicted to be nutrient-rich (Fig. $4 b$ ), whereas in reality some of them are not (Fig. 4a).

Some patches in Fig. $4 \mathrm{~b}$ are blank. The corresponding predicted nutrient values have been filtered out because they are extreme with respect to the range of the calibration data. The patches affected mostly represent forest where the ground is completely hidden.

\section{Discussion and conclusions}

The aim of the study was to optimize fine-scale prediction of vegetation properties by combining high resolution spectral data and digital surfaces models. Mean indicator values for nutrients, moisture and light were used as response variables.

A new approach to deal with a great amount of predictor variables, called the composite modelling, is presented. Given a certain number of observations, the new modelling procedure enables the use of more predictor variables than simple regression, without decrease of the predictive performance.

Exploiting both spectral data and relief characteristics of mire sites results in a powerful modelling of indicator values, with correlations of up to 0.9 between predicted and observed control data values. The predictive power and the accuracy of the model differs for indicator values. Among the tested values, the best predictive power is for the nutrients, whereas the best accuracy is for light.
Developing and testing the model revealed limitations inherent to the method and to the nature of the available data. Some of these limitations are discussed below.

\section{Limitations of spectral and topographical predictor variables}

The basic idea of modelling on spectral data is simple: what looks similar on an aerial picture is assumed to be similar in nature as well. Adding topographical predictor variables to the model extends the concept without altering it substantially.

It will work as long as the underlying assumption is true. But there are floristically different plant communities that may appear physiognomically similar, although the dominating plant species change (Dirnböck et al. 2003). This problem occurs with alkaline small sedge fens and semi dry grasslands in the Swiss mires. The prediction of indicator values is inaccurate for such vegetation types. To find a topographical or spectral variable which would distinguish such similarly appearing units is a possible solution. In the case of spectral variables, additional colour bands may be available in the future due to digital photography.

Another difficulty of the method concerns areas covered by trees or shadow. The stratification procedure presented in this paper can solve the problem only partially. The ground covered by trees or shadow is not visible, i.e., there is no spectral information about it. Modelling in wooded areas using spectral information is restricted to the visible tree canopy surface.

Increasing the resolution of predictor surfaces does not necessarily improve the accuracy of mapping results. In particular pixel-based prediction tools have difficulties in exploiting contextual information within high resolution data sets. In this study an a priori delineation was performed in order to create appropriate spatial units for modelling. The inevitable simplification of actually complex and heterogeneous groupings, which results from the polygon mapping techniques (Goodchild 1992, Bettinger et al. 1996, Walker and Kenkel 2001) is compensated by the extraction of powerful predictor variables including textural characteristics for each polygon.

Spectral inconsistencies within aerial photos can be caused by lens effects (Dean et al. 2000), varying surface structure (Ravan and Roy 1997, Brandtberg et al. 2003), solar direction and viewing angle (Holopainen and Wang 1998, Mikkola and Pellikka 2002) or diffuse soil background reflectance. 


\section{Composite modelling, a new variable reduction method and its limitations}

Composite modelling enables the use of many predictor variables (about 130 in this study, see Table 1), although the number of variables still has to be restricted for several reasons:

- Within the first level models, the number of predictor variables is still limited by the number of observations. So is the number of variable groups entering the second level regression.

- Dealing with a great number of variables by composite modelling in three or more levels (instead of two as described in this paper) is not a solution: the correlation structure of the composite variables entering the highest level regression would be problematic (collinearity of predictor variables, see e.g., Stahel 1995). Further, deriving more and more variables from the same data is likely to produce redundancy.

Composite modelling seems to be a high performance tool to deal with a great amount of predictor variables, even if it does not solve all problems. It can favour a structured and issue-related selection of predictor variables.

Acknowledgements. The study was carried out in the frame of the Swiss mire monitoring program initiated in 1996 at the Swiss Federal Research Institute WSL and funded by the Swiss Agency for the Environment, Forest and Landscape. We are grateful to W. A. Stahel for his advice in statistics, Janine Bolliger for her comments and suggestions and Peter Longatti for linguistic improvements. We thank the two reviewers for their pertinent comments and suggestions.

\section{References}

Baatz, M. and A. Schäpe 2000. Multiresolution Segmentation - an optimization approach for high quality multi-scale image segmentation. In: J. Strobl, T. Blaschke and G. Griesebner (eds), Angewandte Geographische Informationsverarbeitung XII, Wichmann Verlag, Heidelberg. pp. 12-23.

Bajwa, S. G. and L. Tian. 2002. Multispectral CIR image calibration for cloud shadow and soil background influence using intensity normalization. Applied Engineering in Agriculture 18: 627-635.

Bettinger, P., G. A. Bradshaw and G. W. Weaver. 1996. Effects of geographic information system vector-raster-vector data conversion on landscape indices. Canadian Journal of Forest Research 26: 1416-1425.

Brandtberg, T., J. B. McGraw, T. A. Warner and R. E. Landenberger. 2003. Image restoration based on multiscale relationship of image structures. IEEE Transactions on Geoscience and Remote Sensing 41: 102-110.

Broge, N. H. and E. Leblanc. 2001. Comparing prediction power and stability of broadband and hyperspectral vegetation indices for estimation of green leaf area index and canopy chlorophyll density. Remote Sensing of Environment 76: 156-172.

Broggi, M. F. 1990. Inventar der Flachmoore von nationaler Bedeutung. Entwurffür die Vernehmlassung. / Inventaire des bas-ma- rais d'importance nationale. Projet mis en consultation. / Inventario delle paludi d'importanza nazionale. Progetto presentato in consultazione. BUWAL, Bern, Switzerland.

Brossard, T., A. Elvebakk, D. Joly and L. Nilsen. 2002. Modelling index of thermophily by means of a multi-source database on Broggerhalvoya Peninsula (Svalbard). International Journal of Remote Sensing 23: 4683-4698.

Dean, C., T. A. Warner and J. B. McGraw. 2000. Suitability of the DCS460c colour digital camera for quantitative remote sensing analysis of vegetation. ISPRS Journal of Photogrammetry and Remote Sensing 55: 105-118.

Diekmann, M. and C. Dupre. 1997. Acidification and eutrophication of deciduous forests in northwestern Germany demonstrated by indicator species analysis. Journal of Vegetation Science 8: 855864.

Dillon, W. R. and M. Goldstein. 1984. Multivariate Analysis, Methods and Applications. Wiley, New York.

Dirnböck, T., S. Dullinger, M. Gottfried, C. Ginzler and G. Grabherr. 2003. Mapping alpine vegetation based on image analysis, topographic variables and Canonical Correspondance Analysis. $A p$ plied Vegetation Science 6: 85-96.

Dirnböck, T., R. J. Hobbs, R. J. Lambeck and P. A. Caccetta. 2002. Vegetation distribution in relation to topographically driven processes in southwestern Australia. Applied Vegetation Science 5: 147-158.

Draper, N. R. and H. Smith. 1981. Applied Regression Analysis. Wiley, New-York.

Dufrêne, M. and P. Legendre. 1997. Species assemblages and indicator species: The need for a flexible asymmetrical approach. Ecological Monographs 67: 345-366.

Dullinger, S., T. Dirnböck, M. Gottfried, C. Ginzler and G. Grabherr. 2001. Kombination von statistischer Habitatanalyse und Luftbildauswertung zur Kartierung alpiner Rasengesellschaften. Angewandte Geographische Informationsverarbeitung XIII: Beiträge zum AGIT-Symposium Salzburg 2001: 114-123.

Ellenberg, H. 1974. Zeigerwerte der Gefässpflanzen Mitteleuropas. Scripta Geobotanica 9.

Ellenberg, H., H. E. Webwe, R. Düll, V. Wirth, W. Werner and D. Paulissen. 1992. Zeigerwerte von Pflanzen in Mitteleuropa. Scripta Geobot. 18: 1-248.

ESRI 1995. ARC/INFO. Environmental Systems Research Institute, Inc. 1982-1995. Version 7.0.3.

Frank, T. D. 1988. Mapping dominant vegetation communities in the Colorado Rocky- Mountain Front Range with Landsat Thematic Mapper and Digital Terrain Data. Photogrammetric Engineering and Remote Sensing 54: 1727-1734.

Franklin, J. 1995. Predictive vegetation mapping: Geographic modelling of biospatial patterns in relation to environmental gradients. Progress in Physical Geography 19: 474-499.

Gao, X., A. R. Huete, W. G. Ni and T. Miura. 2000. Optical-biophysical relationships of vegetation spectra without background contamination. Remote Sensing of Environment 74: 609-620.

Gégout, J. C., J. C. Herve, F. Houllier and J. C. Pierrat. 2003. Prediction of forest soil nutrient status using vegetation. Journal of Vegetation Science 14: 55-62.

Ginzler, G. and K. De Laporte 2001. High resolution digital surface models for environmental monitoring. Geoinformatics. 1: 2628.

Goodchild, M. F., S. Guoqing and Y. Shiren. 1992. Development and test of an error model for categorical data. International Journal of Geographical Information Systems 6: 87-104. 
Grünig, A., L. Vetterli and O. Wildi. 1986. Die Hoch- und Uebergangsmoore der Schweiz - eine Inventarauswertung. / Les hauts-marais et marais de transition de Suisse - résultats d'un inventaire. Eidgenössische Forschungsanstalt für Wald, Schnee und Landschaft. Birmensdorf, Bericht 281

Guisan, A. and N. E. Zimmermann. 2000. Predictive habitat distribution models in ecology. Ecological Modelling 135: 147-186.

Hawkes, J. C., D. G. Pyatt and I. M. S. White. 1997. Using Ellenberg indicator values to assess soil quality in British forests from ground vegetation: A pilot study. Journal of Applied Ecology 34: 375-387.

Hill, M. O. and P. D. Carey. 1997. Prediction of yield in the Rothamsted Park Grass Experiment by Ellenberg indicator values. Journal of Vegetation Science 8: 579-586.

Holopainen, M. and G. X. Wang. 1998. The calibration of digitized aerial photographs for forest stratification. International Journal of Remote Sensing 19: 677-696.

Huete, A., K. Didan, T. Miura, E. P. Rodriguez, X. Gao and L. G. Ferreira. 2002. Overview of the radiometric and biophysical performance of the MODIS vegetation indices. Remote Sensing of Environment 83: 195-213.

Hutchinson, C. F. 1982. Techniques for combining Landsat and ancillary data for digital classification improvement. Photogrammetric Engineering and Remote Sensing 48: 123-130.

Johnson, R. A. and D. W. Wichern. 1982. Applied Multivariate Statistical Analysis. Prentice-Hall, Englewood Cliffs, New Jersey.

Kienast, F., B. Brzeziecki and O. Wildi. 1996. Long-term adaptation potential of Central European mountain forests to climate change: A GIS-assisted sensitivity assessment. Forest Ecology and Management 80: 133-153.

Landolt, E. 1977. Ökologische Zeigerwerte zur Schweizer Flora. Veröffentlichungen des Geobotanischen Institutes der Eidg. Techn. Hochschule, Stiftung Rübel. Zürich.

Legendre, P. and M. Legendre. 1998. Numerical Ecology. Elsevier Science, Amsterdam.

Lim, K., P. Treitz, M. Wulder, B. St-Onge and M. Flood. 2003. LiDAR remote sensing of forest structure. Progress in Physical Geography 27: 88-106.

Mardia, K. V., J. T. Kent and J. M. Bibby. 1979. Multivariate Analysis. Academic Press, London.

Mikkola, J. and P. Pellikka. 2002. Normalization of bi-directional effects in aerial CIR photographs to improve classification accuracy of boreal and subarctic vegetation for pollen-landscape calibration. International Journal of Remote Sensing 23: 47194742.

Miller, A. J. 1984. Selection of subsets of regression variables. Journal of the Royal Statistical Society Series A - Statistics in Society 147: 389-425.

Miller, A. J. 1990. Subset Selection in Regression. Chapman and Hall, London.

Moore, I. D., R. B. Grayson and A. R. Ladson. 1991. Digital terrain modeling - a review of hydrological, geomorphological, and biological applications. Hydrological Processes 5: 3-30.

Nilsen, L., T. Brossard and D. Joly. 1999. Mapping plant communities in a local Arctic landscape applying a scanned infrared aerial photograph in a geographical information system. International Journal of Remote Sensing 20: 463-480.

Osborne, M. R. 1976. On the computation of stepwise regressions. Australian Computer Journal 6: 61-68.
Persson, S. 1981. Ecological indicator values as an aid in the interpretation of ordination diagrams. J. Ecol. 69: 71-84.

Qi, J., A. Chehbouni, A. R. Huete, Y. H. Kerr and S. Sorooshian. 1994. A modified soil adjusted vegetation index. Remote Sensing of Environment 48: 119-126.

Ravan, S. A. and P. S. Roy. 1997. Satellite remote sensing for ecological analysis of forested landscape. Plant Ecology 131: 129141.

Richards, J. A. 1993. Remote Sensing Digital Image Analysis. An Introduction. Springer, Berlin.

Richardson, A. J. and C. L. Wiegand. 1977. Distinguishing vegetation from soil background information. Photogrammetric Engineering and Remote Sensing 43: 1541-1552.

Schlittgen, R. 2000. Einführung in die Statistik: Analyse und Modellierung von Daten. Oldenbourg Verlag, München.

Stahel, W. 1995. Statistische Datenanalysis. Eine Einführung für Naturwissenschafter. Vieweg, Braunschweig.

Ter Braak, C. J. F. and C. W. N. Looman. 1995. Regression. In: R. H. Jongman, C. J. F. Ter Braak and O. F. R. Van Tongeren (eds), Data Analysis in Community and Landscape Ecology. Cambridge University Press, Cambridge

Treitz, P. and P. Howarth. 2000. Integrating spectral, spatial, and terrain variables for forest ecosystem classification. Photogrammetric Engineering and Remote Sensing 66: 305-317.

Treitz, P. M., P. J. Howarth, R. C. Suffling and P. Smith. 1992. Application of detailed ground information to vegetation mapping with high spatial-resolution digital imagery. Remote Sensing of Environment 42: 65-82.

Walker, D. J. and N. C. Kenkel. 2001. Landscape complexity in space and time. Community Ecology 2: 109-119.

Warner, T. A., D. J. Campagna, C. S. Evans, D. W. Levandowski and H. Cetin. 1991. Analyzing remote-sensing geobotanical trends in Quetico Provincial Park, Ontario, Canada, using digital elevation data. Photogrammetric Engineering and Remote Sensing 57: 1179-1183.

Warner, T. A., D. W. Levandowski, R. Bell and H. Cetin. 1994. Rule-based geobotanical classification of topographic, aeromagnetic, and remotely-sensed vegetation community data. Remote Sensing of Environment 50: 41-51.

White, J. D., G. C. Kroh and J. E. Pinder. 1995. Forest mapping at Lassen Volcanic National Park, California, using Landsat Tm data and a geographical information system. Photogrammetric Engineering and Remote Sensing 61: 299-305.

Wiegand, C. L., A. J. Richardson, D. E. Escobar and A. H. Gerbermann. 1991. Vegetation indexes in crop assessments. Remote Sensing of Environment 35: 105-119.

Wiegand, K., H. Schmidt, F. Jeltsch and D. Ward. 2000. Linking a spatially-explicit model of acacias to GIS and remotely-sensed data. Folia Geobotanica 35: 211-230.

Woodcock, C. and V. J. Harward. 1992. Nested-hierarchical scene models and image segmentation. International Journal of Remote Sensing 13: 3167-3187.

Zar, J. H. 1986. Biostatistical Analysis. Prentice Hall, Upper Saddle River, New Jersey.

Zimmermann, N. E. and F. Kienast 1999: Predictive mapping of alpine grasslands in Switzerland: Species versus community approach. Journal of Vegetation Science 10: 469-482. 